\title{
SOBRE TEIAS E TRAMAS DE APRENDER \\ E ENSINAR: anotações a respeito de uma antropologia da educação ${ }^{1}$
}

\author{
Carlos Rodrigues Brandão**
}

Yaqub, o filho do juiz, disse que certa vez interrogou Bahaudin Nawshband da seguinte maneira:

- Quando eu estava em companhia de Murshid de Tabriz, ele fazia regularmente um sinal para que ninguém lhe dirigisse a palavra, quando estavam num momento de especial reflexão. Mas tu nos és acessível a qualquer momento. Devo concluir que essa diferença se deve à tua capacidade incomparavelmente maior de desprendimento, estando essa capacidade sob o teu domínio, ao invés de ser fugidia? Bahaudin the respondeu:

- Não, tu estás sempre em busca de comparações entre as pessoas e entre os estados. Estás sempre em busca de provas e diferenças, e quando não as buscas procuras semelhanças. Não precisas de tanta explicação em assuntos que estão fora de tais medições. Modos diferentes de comportamento da parte dos sábios devem ser vistos como devidos a diferenças em individualidade, e não em qualidade.

Idries Shah

The Wisdon of the Idiots 
Inter-Ação: Rev. Fac. Educ. UFG, 27 (2): 1-54, jul./dez. $2002 \quad 9$

(pode ser encontrado nas páginas 85 e 86 de $A$ Mente editativa, de Daniel Coleman)

\section{RESUMO}

Em um século de atividade, percorrendo várias situações históricas e vários modelos de pensamento, a antropologia tem incorporado inúmeras temáticas no seu universo de pesquisa. Em alguns momentos e com o esforço de grandes pesquisadores, já se interessou inclusive pelas macro-estruturas políticas e econômicas. Mas ela está sempre voltando ao seu lugar de origem - 0 lugar da pessoa, da individualidade na cultura. Curiosamente, o interesse da antropologia pela educação e principalmente pelo mundo da escola, nunca foi exemplar. Quando encontrado, é quase excepcional. Eis, pois, o investimento do presente texto. Aos olhos da antropologia a educação é cultura, ou seja, faz parte dos sistemas de símbolos e significados de uma determinada cultura. Isso precisa ser sempre mais sistematizado.

Palavras-Chave: Antropologia; Antropologia e educação; Cultura e educação.

\section{ABSTRACT}

In an activiy of a hundred years, going through several historical situation and thoughts patterns, antropology has incorporated many topics in its research universe. At some moments and with na after of great researches, antropology has already showed interst for the macro - structure and economical politics. But it is always coming back to its original place - the people place, cultural individuality.

Interesting, the antropology interest for the education and mainly for the school world, never was considered na example. When it happens, it is 
10 SILVA, Kátia A. C. P. C. Articulação teoria e prática...

almost exceptional. That is why we invest on this text. for the antropology, the education means culture, part of the symbol systems and meanings of a specific cultures. This needs to be always systematized.

Keywords: antropology; antropology and education;culture and education.

\section{Viajando na fronteira}

Todo o campo do saber humano, venha ele como ciência ou não, oscila entre ausências e exageros. Há sempre faltas e sobras e os momentos de equilíbrio entre uma coisa e a outra são raros. Nas ciências humanas, mais ainda. Desde um ou dois séculos atrás andamos sempre às voltas ora com "psicologismo" demais, ora com "sociologismo" demais. Aqui há "estrutura" em excesso e penúria de "história", mais adiante o oposto. Uma "pedagogia da existência" ameaça superar uma "pedagogia da essência" e, de vez em quando, para sermos construtivistas construímos mais divergências do que pontos de encontro. E em lugar de diálogos entre o "lugar do sujeito" e a "dimensão social da educação", assim como a interminável polêmica entre "humanistas" (mas será este o nome mais adequado?) e "behaviouristas" (idem?), alimenta-se a fogueira acesa a meio caminho entre outros divisores eternos de águas e de idéias sobre a psicologia, sobre a pedagogia e sobre os alcances e limites dos olhares das ciências sociais na educação. Somos essencialmente 
o que a herança genética cria em nós desde um momento para sempre? Tudo o que é importante neste ainda tão pouco conhecido processo de socialização tem a ver com o que se passa na psiquê de cada uma e cada um de nós, e o seu limite seriam apenas as relações interativas de pequena escala, de que a família nuclear é o melhor exemplo e onde a sala-de-aulas é quase um limite? Ou, ao contrário, cada uma de nós, as nossas famílias e as salas-de-aulas que habitamos como estudantes e/ou como educadores são dimensões interindividuais ou agenciadas em e como uma determinada cultura que nos cria, recria e molda com poderes muito maiores do que podemos suspeitar pedagogicamente? Por outro lado, existem fontes e ideais universais e universalmente perenes de algo como a bondade, a verdade e a beleza e, como em Sócrates e Platão e, muito mais tarde, em Kant, elas deveriam ser a finalidade da ética, da filosofia, da arte e da educação? Ou partilhamos, pessoas, culturas, povos e eras, de uma busca múltipla e humanamente sempre desigual de sentidos e de significados diante dos quais toda a universalidade humana e social deveria ser relativizada? (Gardner, 1998).

Entre nós, profissionais ou estudiosos da educação, na maior parte dos casos, sobram na teoria, nos métodos e nas práticas o que nos acostumamos a chamar de abordagens psicológicas. Somos testemunhas do proveito e até mesmo de alguns excessos deste múltiplo campo científico de contribuição a quase todos os campos da teoria e da prática 
da educação. Mas eis que de uma maneira desequilibrada faltam os seus equivalentes como abordagens sociológicas. Basta olhar qualquer currículo de curso de pedagogia no Brasil.

E bem sabemos que mesmo dentro do campo da contribuição das ciências sociais às ciências humanas - onde começa uma? Onde acaba a outra? - existem desequilíbrios muito grandes e muito curiosos. Existe aí algo semelhante à desproporção entre um excesso de psicologias diferenciais da superfície do humano (psicologia da aprendizagem, psicologia da inteligência, psicologia da motivação, psicologia da personalidade, psicopedagogia, etc) e uma ausência quase absoluta das psicologias de profundidade (psicanálise, psicologia analítica, etc). Como se o inconsciente não aprendesse. Como se ele e seus desdobramentos não fossem um fator tão importante na vida e no destino do sujeito aprendente, aluno de escola ou não. E eu pergunto se não existiriam demasiadas razões para que, entre Piaget e Vigostsky, todos esses estranhos processos e essas estruturas da psique, devam permanecer até hoje nas áreas de penumbra da formação e do trabalho de um profissional da educação. E, no entanto, basta uma leitura atenta ou uma boa conversa com um terapeuta analítico, ou basta verificar a contribuição direta e indireta de Freud, de Jung, de Adler, de Melanie Klein, de Eric Fromm à compreensão dos mistérios mais interiores das relações nas e entre as pessoas humanas ao longo do processo de socialização, para nos perguntarmos por que 
motivos as suas descobertas e teorias permanecem tão distanciadas da formação de educadores.

Ora, pensemos que vista desde uma boa teoria analítica, a pessoa humana é também e é essencialmente um inconsciente que, não apenas nos ternos anos da infância, mas ao longo de toda a vida projeta símbolos, sentidos de vida, desejos e sensibilidades para além de si mesmo, e constrói assim a sua a face de identidade e realização consciente onde, supõe-se, está tudo o que envolve quase toda a capacidade lógica e afetiva de aprender e, portanto, uma boa parte do trabalho da educadora.

Vivemos afortunadamente tempos em que em todos os campos de criação do saber, há um crescente reconhecimento de que uma reintegração entre as ciências e, até mesmo, entre elas e outras esferas humanas de razão e de sensibilidade, parece ser a única saída em direção à descoberta do novo. Da astrofísica à psicologia estamos cada vez mais mergulhados no desafio de buscar pensamentos, pesquisas e teorias mais e mais interdisciplinares. Mais ousadamente transdisciplinares, dirão alguns, com o aval da própria UNESCO.

Um exemplo muito familiar entre todas e todos nós poderia ser lembrado aqui: o da aprendizagem. Sempre se soube que tanto a inteligência humana quanto uma de suas propriedades mais elementares, o aprender-asaber, nunca possuíram um lugar central de explicação, ainda que em algumas possam ter um lugar mais privilegiado. Mas bem sabemos 
que as ciências e as teorias que centraram a compreensão da aprendizagem em um campo único, produziram resultados muito limitados e bastante efêmeros. $E$ hoje vemos mais do que ontem, mais do que nunca, por toda a parte uma inevitável aproximação entre abordagens sobre a aprendizagem, vindas da genética, da biologia, a etologia, da neuroquímica do cérebro, da psicanálise, da psicologia, e da pedagogia, assim como da história, da antropologia e da sociologia, em busca de avanços certamente diferenciados e peculiares, mas cujos fatos e sentidos de descoberta só se realizam de fato quando postos em diálogo dentro e fora de seu campo. Quando cada vez mais amplamente partilhados. Em tempos de inteligências múltiplas, já é bem a hora de multiplicarmos os nossos olhares sobre a inteligência e sobre a própria aprendizagem.

Pois o que poderia parecer algo tão simples e tão redutível a uma meia dúzia de formulas e a uma boa teoria única, na realidade esconde nos gestos de uma criança, toda a complexidade do universo da consciência. E ela vai dos mistérios da decifração do DNA até a compreensão sobre como em cada cultura o acontecimento da aprendizagem - e de tudo o que a envolve em seu dia a dia social - é imaginado, codificado e vivenciado entre os seus sujeitos.

Uma terra-de-todos-e-de-ninguém, divide e une cientistas da vida, psicólogos, pesquisadores sociais e educadores. E ela se abre a novas descobertas e a novas teorias, ali onde cada vez mais a 
exclusividade e a uni-centralidade são hoje uma ilusão de tipo quase fetichista. Assim, o mistério do aprender estende-se como nunca a uma possibilidade polissêmica de descobertas e de integrações de idéias empíricas e teóricas. Uma multiplicidade de olhares e de compreensões que pouco a pouco - a não ser entre raros e arrogantes reducionistas - descobre que não há mais caminhos únicos e nem olhares exclusivos. De outra parte, tal como acontece também entre astrofísicos, pesquisadores da teoria dos quanta, ou entre biólogos e geneticistas, onde até há algum tempo atrás parecia haver uma possibilidade de formulação de explicações claramente sistemáticas e definitivas a respeito dos fenômenos do cosmos, da vida, da psique ou da cultura, existem agora aproximações científicas de e entre conhecimentos diversos. De conhecimentos efêmeros e voltados muito mais à formulação de novas perguntas do que à acumulação de respostas duradouras. Teorias sobre a realidade abertas à indeterminação, tal como ela própria parece se mostrar a cada dia mais. $O$ que 0 antropólogo norteamericano Clifford Geertz disse um dia alhures a respeito da antropologia pode valer para qualquer outra esfera de pesquisa do fenômeno humano. Faz algum tempo deixamos de ser ciências positivas em busca de leis e nos tornamos ciências interpretativas a procura de significados.

Assim, para tentar compreender tanto as estrelas quanto as escolas, estamos cada vez 
mais obrigados a uma aproximação de horizontes, a uma convergência de dúvidas e de perguntas, e a uma franca interação de descobertas e de teorias. Mas é necessário termos em conta que isto nada tem a ver com um novo enciclopedismo. Nada a ver com uma mistura apressada de idéias ou, pior ainda, com uma superposição mal digerida de domínios do conhecimento. Ao contrário, o que temos à nossa frente é uma convergência fascinante de campos do saber, que nos obrigará a um esforço cada vez mais redobrado de estudos e de pesquisas.

Enfim, vemos que entre nós, pesquisadores e praticantes do conhecimento a respeito da pessoa, da cultura e da sociedade, o caminho a percorrer para buscar compreensões passa pela integração e o equilíbrio sempre necessário, sempre instável, entre campos e domínios diversos de conhecimentos científicos Passa pela interação entre convergências de ciências e outras esferas de saber, sentir e pensar: a filosofia, a espiritualidade, a arte a imaginação humana em todos os seus campos, em todas as suas dimensões e em todas as suas possibilidade de criação. E passa pela abertura corajosa à indeterminação, à procura incessante de algo sempre nunca inteiramente explicável, porque nunca mecânico e, assim, nunca inteiramente redutível a fórmulas, a números ou a leis.

\section{Educação e cultura: a educação como cultura}

Pois bem, olhada desde o horizonte da 
antropologia, toda a educação é cultura. Toda a teoria da educação é uma dimensão parcelar de alguns sistemas motivados de símbolos e de significados de uma dada cultura, ou do lugar social de um entrecruzamento de culturas. Assim também, qualquer estrutura intencional e agenciada de educação constitui uma entre outras modalidades de articulação de processos de realização de uma cultura, seja ela a de nossos indígenas Tapirapé, a da Grécia dos tempos de Sócrates ou a de Goiânia ou Chicago de hoje em dia. Constitui as elaborações intencionais de uma cultura que pensa e que põe em ação as suas alternativas e estratégias de pensamento, de poder e de ação interativa, por meio das quais o seu mundo social cria, diferencia, consagra e transforma boa parte do que ela própria é em um dado momento de sua trajetória. Do que ela é e do que ela possui e continuamente entre guerra e paz - integra para se manter e perpetuar pelo menos por mais algum tempo.

Estas construções históricas e cotidianas da cultura são: saberes, valores, códigos e gramáticas de relacionamentos entre as diferentes categorias de atores culturais. São também as várias espécies duradouras ou transitórias de metodologias de ações motivadas, assim como são as práticas instrumentais de algum trabalho destinado a lograr determinados objetivos. Sim, mas objetivos relacionados a quê? Ora, relacionados a tudo o que consideramos como as razões sociais do ser da própria educação. Relacionados à necessidade e à 
nossa capacidade de lidarmos com o nosso mundo natural adaptando-o criativamente ao homem e, não, adaptando-nos a ele, tal como fazem os animais, que nem criam culturas e nem precisam de escolas, como lembraria Marx. Relacionados à circulação de sentidos, de significados e de sensibilidades dentro de e entre círculos mais ou menos amplos de pessoas. Relacionados ao trabalho pedagógico de realizar a reprodução cultural de diferentes tipos de sujeitos sociais. Isto é: o difícil transformar indivíduos biológicamente introduzidos em uma sociedade, em pessoas culturalmente construídas através de interações significativas da(s) e na(s) cultura(s) de um dado universo social.

Em um artigo a respeito da infância como um enigma, Jorge Larrosa (1998, p. 71) recorda uma idéia trivial, escrita algum dia por Hannah Arendt. Ela é tão simples e tão evidente que parece tolo dizer isto que, entretanto, foi escrito assim: a educação tem a ver com a natalidade, com o fato de que constantemente nascem seres humanos no mundo. Claro, há pouco e há tudo o que falar a respeito. Educamos crianças e jovens porque eles nasceram. Porque vieram ao mundo sem saber quem são, quem somos nós que os antecedemos, e o que é "este mundo" que compartiremos juntos por algum tempo e que, um pouco adiante, deixaremos para eles, adultos. Educamos os que nascem porque esta é a única maneira - escolar ou não - de criar pessoas e recriar mundos de interações entre pessoas. Mundos que culturalmente transformam atos em gestos e 
gestos em ações regidas por acordos sociais de sentidos e por consensos de significados. Educamos para que o outro - a educanda, o educando - sejam como nós ou, se possível, melhores do que nós. Para que sejam, tal como nós acreditamos que somos, habitantes conhecedores, conscientes, e criativos de um mundo cotidiano. Um mundo relacional do dia-a-dia e, ao mesmo tempo, o complexo cenário histórico de experiências interpessoais que não podem existir a não ser através dos gestos de intercomunicação entre tipos de pessoas socializaddas e em socialização. Isto é, educadas e inseridas ainda em algum momento da educação.

Ora, mas não é este reproduzir o outro como eu mesmo, o que tem sido hoje em dia bastante revisto e criticado por tantas e tantos educadores? Pois em termos caros ao interacionalismo simbólico, educamos para tornar interior a pessoas uma cultura que as antecede, uma cultura que as conforma e que, em contrapartida existe nas e através da interações entre as pessoas.

Assim sendo, para a antropologia todo o acontecimento da educação existe como um momento motivado da cultura. Mas toda a cultura humana é um fruto direto do trabalho da educação. Mais do que o aborrecido dilema do ovo-e-da-galinha, proponho que esta obviedade seja considerada como uma boa estrada de ida-e-volta. Pois somos, seres humanos, o que aprendemos na e da cultura de quem somos e de que participamos. Algo que cerca e enreda e vai da língua que falamos ao amor que praticamos, e da 
comida que comemos à filosofia de vida com que atribuímos sentidos ao mundo, à fala, ao amor, à comida, ao saber, à educação e a nós próprios.

No entanto, desde a criação da moderna antropologia, com o passar do tempo houve e há um distanciamento grande e persistente frente a tudo o que tenha a ver com as estruturas e os processos intencionais e agenciados de socialização pedagógica de crianças, de adolescentes e de jovens. Até o presente momento, isto é, mais ou menos um século após a criação da antropologia moderna, e também mais ou menos um século após o surgimento da moderna psicologia e da eclosão de algumas das teorias mais relevantes no campo da pedagogia, somos testemunhas de um misterioso hiato entre a teoria antropológica e a educação, enquanto um campo especial de conhecimento e de práticas sociais. Uma explicação rudimentar para este fato pode estar na própria antropologia.

Somos, antropólogas e antropólogos, praticantes de uma estranha ciência dirigida ao mundo dos adultos, ao contrário de boa parte do que se pratica na psicologia.

Crianças e adolescentes atraem a nossa atenção mais como participantes de rituais de passagem, do que como lentos sujeitos submetidos a um longo "trabalho de saber"2. Guardadas as proporções, é como se a uma antropologia nascida da pesquisa de observação participante junto a comunidades tribais, interessassem muito mais os ritos de formatura e o destino social do "formado", do 
que o trabalho escolar cotidiano de sua formação através da aprendizagem, escolar ou não.

É bem verdade que houve sempre exceções. No entanto, em apenas raras ocasiões elas foram visíveis e causaram algum impacto maior. Uma delas foi a da tendência ou escola norte-americana de cultura e personalidade. Ela teve uma curta e fecunda vida iniciada e encerrada mais ou menos entre as décadas de 40 e a de 60 , e motivou pessoas como Margareth Mead, Ralph Linton, Ruth Benedict e Abrahan Kardiner. Seu interesse esteve concentrado sobre as relações culturais de socialização e sobre os efeitos delas na formação social de um determinado tipo de "personalidade "e de "cultura". Apenas de maneira acidental a educação formal e a instituição escolar foram alvo de seu interesse. Até porque quase toda a sua etnografia foi realizada junto a culturas indígenas e tribais, quase sempre alheias à escola e ao profissional da educação. Até hoje as críticas da antropologia às escolas missionárias e suas congêneres costumam ser ferozes. E apenas de poucos anos para cá abriu-se entre antropólogas e educadoras um interesse convergente em torno à educação dos povos indígenas. Isto é, sobre como, nas relações entre as culturas indígenas e o "mundo dos brancos", a formação escolar das pessoas indígenas deve ser realizada, já que isto tende a ser inevitável.

Tomemos dois livros conhecidos: a construção social da realidade, ${ }^{3}$ de Peter Berger e de Thomas Luckmann, e cultura, um 
conceito antropológico, de Roque de Barros Laraia. ${ }^{4}$ São dois exemplos que me vêm à cabeça. Poderiam ser outros.

Ora, em ambos aqui e ali é enfatizada a dimensão dinâmica, inter-geracional e, portanto, socializadora da cultura. No primeiro livro esta questão constitui todo um longo capítulo 3: a sociedade como realidade subjetiva. No segundo ela aparece em algumas citações de Laraia tomadas de antropólogos pioneiros. É isto o que interessa aqui. Ao arrolar uma série de formulações de Kroeber sobre o que é a cultura e como ela "funciona", é lembrado que: $1^{\circ}$. A dquirindo cultura, o homem passou a depender muito mais do aprendizado do que a agir através de atitudes geneticamente determinadas: 2 .

Como já era do conhecimento da humanidade desde o iluminismo, é este processo de aprendizagem (socialização ou endoculturação, não importa o termo) que determina o seu comportamento e a sua capacidade artística ou profissional.

Em vários outros textos teóricos e etnográficos de um período que vai dos primórdios da antropologia até pelo menos final dos anos 50 deste nosso século já quase no fim, está sempre colocada como uma evidência e como um dilema, a interação constitutiva entre a cultura estabelecida em qualquer sociedade e os processos, agenciados ou não, de socialização e/ou de endo-transmissão de saberes e de valores entre gerações e entre categorias de pessoas.

Estes estudos de antropólogos e etnógrafos 
queriam dizer o que em boa medida esquecemos mais tarde. Queriam dizer o quê? Ora, que existe uma dimensão da antropologia que deveria estar voltada à compreensão dos processos culturais da socialização. Que deveria estudar a fundo tudo o que acontece nas diferentes situações sociais de endo e de exo-transmissão, durante a circulação de sentidos e de significados de teor propriamente pedagógico. Situações em que, afinal, de alguma maneira se ensina-e-aprende o que é importante para que indivíduos biológicos se tornem pessoas sociais. Ou seja, o aprendizado sequente e contínuo a respeito dos saberes de sentido de vida e compreensão do mundo; das práticas de produção material dos bens da vida; das gramáticas sociais que tanto configuram a ordem dos relacionamentos em cada um dos campos de interações humanas, quanto "criam" atores culturais submetidos (às vezes nem tanto) aos seus sistemas de valores, de preceitos, de normas e de regras diretas do agir humano. Enfim, tudo o que tem a ver com a educação, mesmo quando ela não seja ainda a educação pensada, prevista, formatada (tornada uma norma de ação) e realizada no seu lugar preferencial: a escola, segundo a sua versão ocidental, da Grécia até nós.

Ora, aconteceu que de um momento em diante, todo este fascinante trabalho cultural múltiplo por meio do qual a sociedade põe a nu a face ao mesmo tempo mais inocente e mais crucial de si mesma, acabou sendo deixado aos cuidados da psicologia e das 
ciências afins, inclusive a pedagogia. Uma das dimensões mais essenciais de tudo o que envolve a educação foi tornada opaca, sem sentido, isenta de perguntas, vazia de respostas. Do tripé em que ela deveria estar assentada: a pessoa humana, a sociedade e a cultura, faltou um dos pés de apoio.

Entre as suas teorias e a prática etnográfica da pesquisa de campo, a antropologia saiu pela porta dos fundos dos cenários onde acontecem a história social e o cotidiano interativo das trocas de afetos e de saberes, de símbolos e de significados, de poderes, de conflitos e de alianças, de frustrações e de resultados do encontro entre pessoas culturalmente situadas de um lado ou do outro do trabalho de ensinar-e-aprender.

A escola. Um cenário aparentemente inocente e quase saído das histórias de contos de fadas, na ilusória pureza do pequeno teatro cotidiano de uma sala-deaulas. Mas um cenário onde, às voltas com as energias e as matérias mais misteriosas da realidade cultural - o conhecimento, a circulação do conhecimento e o aprendizado infindo do conhecimento - a pessoa humana vive o momento mais essencial de sua própria condição. Pois ali ela experimenta o trabalho pensado e vivido, entre o quadro-negro e as filas geométricas das carteiras, de uma boa réplica do drama interativo da própria metáfora múltipla da vida social. Uma metáfora de nós mesmos, onde sob a aparência de estarmos aprendendo "coisas para a vida" (o lado intencionalmente utilitário educação) estamos empenhados na busca de um sentido para 
nós e para ela, a vida. Um cenário de relacionamentos entre crianças e adultos, através do sentido e do saber, onde o que existe de mais importante entre nós acontece diariamente. Acontece quando em cada escola o saber da cultura, adormecido nos livros e nas mentes, acorda e é ressuscitado neste pequeno milagre que nos faz humanos, cujo nome é "aula", e de cujas originalidade e grandeza estamos mais esquecidos, mais do que devíamos. ${ }^{5}$

Pois no pequenino e grandioso círculo da sala-de-aulas o que a educação pretende, ou devia pretender, que seja feito, é o próprio trabalho através do qual são recriadas e comparticipadas e transferidas de uma pessoa a outras, de um grupo humano a outros, de uma instituição a pessoas ou a grupos humanos, nada menos do que aquilo que se sabe, se lembra (a misteriosa função pedagógica da memória) se pensa, ou se crê em uma cultura humana.

E ao transformar "isto" em uma prática de intertrocas do sentido através do saber, em todos o seus planos, em todos os seus níveis, em todas as suas dimensões situadas dentro e fora dos recantos da escola, a educação lida com a experiência cotidiana mais regular, mais estável e mais eficaz de criação e circulação de visões de mundo, de busca de filosofias do destino e de sentidos para a vida humana, de lógicas do puro saber, de éticas e de gramáticas dos intercâmbios humanos, dos tantos feixes de ciências, das artes (cujo lugar na escola deveria voltar a ser tão mais desmesurado!) e também, porque não? dos 
mistérios e das crenças das religiões e suas espiritualidades.

Não deve parecer estranho o fato de que em quase todos os artigos apresentados na mesa redonda: antropologia e educação interfaces do ensino e da pesquisa, realizada no DECISAE da Faculdade de Educação da UNICAMP em 1996, e depois publicados no número 43 dos Cadernos do CEDES, em 1997, uma referência a Franz Boas tenha estado sempre presente. ${ }^{6}$ Ele foi um dos pais fundadores da moderna antropologia, e o seu historicismo cultural dava ao sujeito e à subjetividade um lugar na análise da cultura que em boa parte se perdeu nos anos seguintes.

Durante largos anos a antropologia deixou na penumbra quase tudo o que tem a ver com as estruturas e relações de reprodução do saber através da socialização escolar de crianças e de jovens. Isto é: a educação. Algo que as sociologias da Europa, dos Estados Unidos da América e mesmo das culturas científicas periféricas nunca deixaram de lado, ainda que raramente uma sociologia da educação tenha sido área nobre nas ciências sociais. Mais ainda. Por algum tempo a antropologia deixou em segundo plano até mesmo todo um repertório essencial de questões relativas ao sujeito humano, ao lugar da individualidade na cultura e aos relacionamentos interativos entre pessoas e, não apenas, entre atores sociais. Foi quando tudo o que de algum modo pudesse parecer uma abordagem de tipo "psicologista" tendia a ser silenciado ou, como dizem os próprios 
antropólogos: relativizado.

Apenas nos últimos 20 ou 30 anos a antropologia - herança de Émile Durkheim muito mais do que de Sigmund Freud, não esquecer - iniciou o caminho de volta ao lugar da pessoa na cultura. Alguns recentes trabalhos brasileiros são notáveis neste sentido. ${ }^{7}$ No entanto, repito, um interesse da antropologia pela educação e, de maneira especial, pelo mundo da escola, é ainda hoje muito pequeno, quase excepcional.

Em uma outra direção, nos últimos anos o educador descobriu as abordagens de estilo antropológico. Descobriu as abordagens fundadoras ou derivadas do interacionalismo simbólico na sociologia do cotidiano. ${ }^{8}$ Este fato que abre horizontes inéditos e desafiadoramente muito fecundos, começou a acontecer quando a teoria e a pesquisa praticadas nas faculdades de educação, de maneira especial, descobriram, ao mesmo tempo: o sujeito pessoal na escola (a pessoa que existe dentro do aluno e a mulher subjacente à professora); o cotidiano escolar, as relações interativas não exclusivamente pedagógicas; as teias e tramas de sentidos, sensibilidades, socialidades e saberes no interior da escola e nos entrecruzamentos entre ela e os outros tempos e espaços que a educação co-habita na e como uma cultura; a identidade social (onde antes se percebia a personalidade genérica do indivíduo) e, por conseqüência, as abordagens interpretativas e os estilos qualitativos de pesquisa e de interpretação. Descobriu ainda a diferença e o direito à diferença na educação e através da 
educação. Tempos de multiculturalismo.

Um número grande e crescente de artigos e de livros a respeito da "cultura na escola "e da "pesquisa qualitativa na educação" é o melhor indicador disto. ${ }^{9}$ Uma outra variação tem sido um certo deslocamento ou, melhor ainda, uma virada de convergência de focos e de olhares provenientes de áreas exclusivamente psicológicas, para os intervalos de um ponto de encontro entre a psicologia e as ciências sociais. Acredito que este promissor não significa uma perda de qualidade da contribuição das teorias e das pesquisas empíricas da psicologia na educação. Ao contrário, tudo isto aponta para um enriquecimento e uma abertura de horizontes de um grande valor, pois o que justamente se deve objetivar são estas intercomunicações entre campos do saber dirigidos à educação. Estas inter e transdisciplinaridades através das quais a própria psicologia redescobre e incorpora ao seu conhecimento, ao mesmo tempo, as redes dos neurônios do cérebro e as teias da inteligência da cultura.

Tomemos um exemplo único entre tantos. Que ele seja, de propósito, algo aparentemente muito simples e até mesmo secundário. Apenas na aparência, claro. Até há poucos anos atrás, os sujeitos sociais envolvidos nas estruturas e nos processos da educação, eram representados ao olhar da pesquisa como agentes das funções dos trabalhos de administrar, de ensinar e de aprender. A própria educação e as suas instâncias e regularidades institucionais de trabalho pedagógico, a começar pela escola, 
ocupavam todo o lugar reservado aos "objetos e objetivos de estudo". Uma margem muito pequena de tolerância científica era deixada aberta para a vida cotidiana na escola, assim como para a realidade existencial (e não apenas pedagógica) das pessoas na escola, e para os jogos misteriosos de suas interações. Uma abertura menor ainda era dada ao acontecimento imprevisível das culturas na, contra e através da escola, e para as maneiras como as próprias escolas são momentos peculiares de culturas em ação, principalmente quando não sabem disto.

Hoje em dia novos olhares e outros interesses sacodem este universo pedagogizado demais, psicologizado demais até aqui. Professoras e professores são chamados a falar de suas vidas, de suas pessoas totais, de seus sonhos e de seus projetos como seres humanos e, até mesmo, como educadores. Aos poucos aprendemos com vizinhos de outras ciências, que uma coisa é como se é e se comporta dentro da armadura de uma situação artificiosamente experimental. Outra é como se vive e como se interage no interior de um cenário "natural" de vida cotidiana. Quantos passos gigantescos foram realizados no campo do comportamento animal, quando biólogos e psicólogos experimentais saíram dos laboratórios e da frente das pequeninas jaulas de seus macacos, e foram pesquisar e compreender, lado a lado com os etnólogos (lembrar a montanha dos gorilas) como os seres com quem compartimos o mistério da vida são, quando vivem livres em seu "meio 
natural". Em que "jaulas" estão ainda as crianças a quem dirigimos as nossas perguntas?

Aos poucos o "mundo da educação" se revela na sua inteireza humana, isto é, cultural. Surgem nele então as pessoas inteiras e interativas envolvidas na educação. Surgem e podem afinal falar as suas representações de si-mesmos; as suas visões de mundo (algo bastante além da simples ideologia política); as suas experiências cotidianas dentro e fora do círculo da escola; as suas vidas de pessoas inteiras, ali onde antes a educadora ou o aluno eram vistos e interpretados apenas enquanto produtores de algum tipo de trabalho na educação.

Ao olhar um lado e o outro do pequeno lugar de encontros de que falo aqui, parece que estamos diante do seguinte. De parte dos estudiosos vindos da educação, há uma redescoberta da escola como um lugar de cultura. Como um múltiplo e fascinante cenário aberto à pesquisa de interações significativas entre pessoas e entre pessoas e instituições situadas aquém e além de um domínio exclusivamente pedagógico, embora sempre relacionadas ao universo da educação. De parte do pessoal da antropologia, surge uma tentativa ainda muito tímida de pensar o lugar e a dinâmica da vida e das intercomunicações sociais na educação e no lugar-escola como um contexto privilegiado do acontecimento cotidiano da cultura. 


\section{Religião e educação: um paralelo bom para se pensar}

Como durante vários anos estive bastante envolvido com estudos e pesquisas de antropologia da religião, arrisco fazer aqui um paralelo entre os estudos sociais sobre ela e os relativos à educação. Bem sei que este confronto pode não ser devido, já que as duas "realidades" são diferentes o bastante para não poderem sequer serem aproximadas em uma comparação. Mas o que interessa aqui é buscar, através dela, algumas respostas a uma intrigante perplexidade, pelo menos para nós, cientistas sociais. Ela poderia ser desdobrada nas seguintes perguntas. Porque que é que, sobretudo nos últimos cincoenta anos há um repertório tão grande e crescente de historiadores, de antropólogos, de sociólogos e de filósofos interessados no estudo do fenômeno religioso em todo o mundo? Porque será que se multiplicam, por toda a parte, encontros, simpósios e congressos ao redor da religião, envolvendo uma qualidade tão rica e tão diversa de estudiosos teóricos e de pesquisadores de campo? E porque será que, em contrapartida, é tão pequeno o número de cientistas sociais e mesmo de pensadores da filosofia entre nós, de fato interessados no estudo persistente da educação? Porque isto acontece se há um reconhecimento universal sobre o valor e a relevância social da educação? Porque é que sendo, tanto ou mais do que a religião, um acontecimento da sociedade, da história e da cultura, onde a 
participação de estudiosos de vários campos

é indispensável, afora o pequeno círculo restrito dos especialistas em alguma das faces do "fenômeno pedagógico", a educação atrai uma diversidade tão pequena de investigadores, inclusive entre os das novas gerações de cientistas sociais? ${ }^{10}$

Arrisco respostas. Uma delas poderia estar no fato de que talvez o mundo das políticas, das práticas e dos estudos sobre educação tenha fechado e siga estreitando demais o círculo das suas questões. Tornou-as técnicas demais, especializadas e subdivididas demais. Encerradas demais sobre si-mesmas e por muito tempo. Fiel ao paralelo proposto aqui, trago um exemplo simples e espero que ele nos ajude: a identidade. Ninguém de nós pode ignorar a vocação inevitável e o poder como criadorade-identidades, atribuídos por tradição e por direito à educação. Acaso, em seu sentido mais amplo e mais generoso, que outra "coisa" ela é, senão isto: uma unidade cultural agenciada e responsavel pela criação de tipos de pessoas e de identidades através da aquisição motivada e sistemática de tipos de saberes, de valores, se sensibilidades?

No entanto, pelo menos desde o ponto de vista do interesse de pesquisa de cientistas sociais, esta dimensão do ser e da metáfora do destino da pessoa parece estar muito mais presente e parece ser muito mais atraente no campo da religião do que no da educação. Pode-se mesmo dizer que do ponto de vista da antropologia aqui no Brasil, existem mais trabalhos - e vários deles muito bons - sobre 
o candomblé, enquanto um atribuidor de identidades culturais e um formador de tipos de sujeitos sociais através da confissão e da prática religiosa, do que sobre a educação.

Claro, há mudanças notáveis e falei acima sobre elas. Mas se formos colocar de um lado toda a fecunda multiplicidade dos olhares e toda a densidade das perguntas postas por gerações passadas e pela geração presente de cientistas sociais sobre as religiões indígenas e populares no Brasil e, do outro, sobre a realidade e os acontecimentos da educação, veremos que há uma desigualdade espantosa. Os cultos afro-brasileiros, por exemplo, têm sido visitados por uma constante diversidade de historiadores, de psicanalistas, de sociólogos e de antropólogos nacionais e estrangeiros. Há um interesse constante por tais estudos cuja proporção chega mesmo a espantar. Da história mítica e "oficial" do culto à simbologia dos cantos e das vestimentas, da interpretação dos mitos à leitura crítica das relações de aliança e conflito dos agentes religiosos, praticamente pergunta alguma deixou de ser feita a mães e a paisde-santo. Não são poucos, ontem e hoje, os cientistas sociais bastante conhecidos pela qualidade de seus trabalhos que estão sempre, ou que estiveram por muito tempo interessados no estudo de algum sistema de religião popular. Poderá ser dito o mesmo a respeito do interesse do pesquisador social pela educação?

Tal como a educação, a religião é um território de trocas de bens, de serviços e de significados entre pessoas. Tal como as da 
educação, as agências culturais de trabalho religioso envolvem hierarquias, distribuição desigual do poder, inclusões e exclusões, rotinas, programas de formação seriada de pessoal e diferentes estilos de trabalhos cotidianos. Mas talvez uma diferença esteja em que a religião celebra ritualmente as suas rotinas, enquanto a educação rotiniza até mesmo as suas celebrações. Daí porque é sempre necessária uma alta dose de imaginação para se fazer uma pesquisa e se escrever um texto denso e de fato absorvente (no sentido dado por Clifford Geertz a estes adjetivos) a respeito do cotidiano escolar. Mas então é preciso olhar com esperança as novas pesquisas a respeito da cultura do cotidiano na escola, assim como todo o trabalho pioneiro e criativo destinado a revivificar este cotidiano, em algumas experiências que pretendem negar uma triste vocação da escola como o lugar da rotina amorfa e da perda do sentido na busca do saber?

Olhada "em", a religião é um fascinante campo de intercomunicação e de intercâmbio entre pessoas e entre "as pessoas e os seus símbolos". É também um cenário muito atraente de criação e de recriação de fatos sociais e de metáforas culturais.

Aparentemente rotineira e rotinizadora do carisma (ver Max Weber) quase sempre a religião é o lugar do acontecimento da maravilha, da densidade simbólica e da imprevisibilidade. Pois até em um sistema religioso ancestral e aparentemente arcaico, onde parece que tudo o que havia para 
acontecer já aconteceu, na verdade, tudo está sempre acontecendo. Até mesmo o que parece ser mais materialmente "econômico" ou mais previsivelmente "político" na religião, sugere estar sempre envolto pelo poder fascinante do rito, do inesperado, do mito, da magia e do milagre.

Enquanto, ao contrário, no previsível campo das relações sociais da educação toda a metáfora tende a se reduzir à lógica, todo o rito à rotina e todo o imaginário a alguma forma enquadrada de ideologia: as da educação e as outras.

Olhada "entre", a religião é um campo aberto de e a interações multiformes. Aberta a interlocuções entre ele mesmo (o campo "propriamente religioso" de Pierre Bourdieu) e todos os outros: da economia do país à sexualidade das adolescentes. Mesmo quando considerada desde o ponto de vista de sistema confessional muito fechado, muito "fundamentalista", como o caso de algumas denominações do pentecostalismo, a interpretação social da religião obriga a estender o olhar às "tramas e teias" tecidas dentro de seu mundo e entretecidas com as de alguns, vários ou todos os de outros campos da vida social e da metáfora cultural. Mas de pelo menos 15 anos para cá muita coisa tem mudado e podemos prever que isto seja apenas o começo de transformações surpreendentes. Em pouco tempo uma boa parte do conhecimento científico sobre a escola e sobre a educação deverá ser construído por equipes interdisciplinares de investigadores. A multiplicidade das questões 
que o imaginário e o trabalho pedagógico estão há todo o momento propondo, sobretudo agora, quando aberta a novas alternativas e estendida a domínios não imaginados a duas décadas atrás, está convocando e convocará cada vez mais esta integração de áreas e de planos diversos do conhecimento humano.

Algumas páginas atrás eu tomava o exemplo da aprendizagem, para lembrar como a decifração de seus segredos deixa em definitivo de ser atribuição de uma categoria única de cientista e se torna um campo aberto a uma crescente integração de abordagens associadas. Acredito que fora situações e áreas de pesquisa muito especializadas, esta tendência de pesquisa multidisciplinar será progressivamente dominante. Se este é o caminho encontrado pelo que nos acostumamos a chamar de "ciências de ponta", não devemos imaginar que o mesmo deva estar começando a acontecer no campo das ciências humanas e, entre elas, no círculo ainda precariamente construído pelas que configuram os estudos sobre e à volta do fenômeno da educação?

Podemos antever o momento em que certos temas como: "a aprendizagem", "o trabalho docente", "a formação de educadores", "o imaginário escolar", "os ciclos da vida humana", "a cultura do cotidiano da escola", "a identidade do educador", serão tratados não apenas por investigadoras submetidas ao dever de uma tese ou de mais um artigo, mas por amplas equipes múltiplas e francamente dialógicas. Será então quando os elos e os 
eixos de uma educação des-centrada dos circuitos de si-mesma e re-centrada nos círculos interligados e estendidos à vida, à pessoa, à cultura e à sociedade, deverão se constituir como as novas unidades temáticas da busca de conhecimento sobre algo que envolve todo ele, mas vai muito além do puro e simples "trabalho pedagógico".

Algo assim já está começando a ocorrer em campos vizinhos. Durante algum tempo de meus últimos anos na UNICAMP estive trabalhando muito próximo de um grupo dedicado aos estudos do meio ambiente, centrado no Núcleo de Estudos e Pesquisas Ambientais (NEPAM). Embora "ali" o cientista por excelência seja o ecólogo, havia entre nós a consciência de que o conhecimento a ser construído, entre pesquisas e debates, estava mais ou menos por igual distribuído entre várias vocações de teoria e de investigação. O próprio GT de Ambiente e Sociedade, da ANPOCS, era um outro desses territórios acadêmicos "de todos e de ninguém". Havia entre nós cientistas sociais, economistas e cientistas da natureza. Havia um fecundo consenso em nossos diálogos e mantínhamos um ponto de partida centrado na idéia de que éramos uma comunidade diferenciada, com idéias e pesquisas próprias, de pessoa a pessoa, mas onde tudo o que de fato importava deveria surgir de um trabalho comum e diferenciado. O que tínhamos a fazer em comum surgia a cada momento justamente do que trazíamos de diferente, uns diante dos outros.

Ora, se a pedagogia pode ser pensada 
também como uma ecologia da pessoa humana, com mais razões o seu campo de teorias, de práticas e de metodologias não deveria ser, de igual maneira, aberto e múltiplo? Se assim vier a ser, poderá chegar então o tempo em que um olhar sobre os mundos da educação revelará, por debaixo da norma, da rotina, da estrutura institucional, do método e da didática, um universo cotidiano cheio de vida e de densidade cultural. Um atraente e misterioso reduto de símbolos e de metáforas, de imprevistos e de criatividade, de rostos humanos únicos e fascinantes, por debaixo da às vezes tão uniforme máscara do educador.

Falei antes dos estudos sobre a religião e do ambientalismo, como lugares da construção do conhecimento aberta a interações, integrações e indeterminações raras na pesquisa e na teoria sobre a educação. Mas será que vocês já repararam como algo mais ou menos assim está acontecendo até mesmo no mundo das empresas? É de ver sisudos empresários em cursos e em treinamentos, desafiados a se fazerem representar ou, pelo menos, imaginar, de palhaços, de feiticeiros, de equilibristas, de escaladores de montanhas e de conquistadores de novos planetas, para aprenderem a ser empresários mais produtivos. Não é nada estranho que uma nascente antropologia do mundo empresarial floresce e ganha adeptos. Pois eis que também entre empresários e gerentes, descobre-se tardiamente que o mundo deles também é uma dimensão especializada (e 
não raro muito perversa, ainda que eles nunca confessem) da cultura.

Assim como há milênios e por razões e com sentidos iguais e diversos, os agentes e fiéis do mundo da religião puderam e seguem podendo ser: sacerdotes e profetas, magos e feiticeiros, honestos e ladrões, criadores ou seguidores de uma versão do fim-do-mundo, hetero e homossexuais, salvadores do mundo e buscadores de si-mesmos, teólogos, poetas e alucinados, conservadores e anarquistas, humanos, anjos e semideuses. Enquanto aos olhos de quem os investiga para compreendêlos e à escola, os sujeitos da educação podem ser apenas, o tempo todo:

educadores-e-educandos, professoresalunos-e-pais-de-alunos, supervisores-ediretores. Como se a identidade da função de quem está na escola recobrisse a totalidade do ser e da metáfora da pessoa que ali está por um momento. Nem que este momento seja quase todos os dias do cotidiano e quase todos os meses de quase toda a vida. ${ }^{11}$ O que estou propondo é uma espécie de passagem do cotidiano da escola para a educação do cotidiano. Isto significaria, em primeiro lugar, o abrir as portas da escola e sair a buscar compreender os mundos circunvizinhos, antagônicos, próximos e remotos onde estão, onde vivem e convivem com suas culturas do cotidiano os próprios personagens da vida escolar. Significaria, em seguida, o trazer para o campo da educação todas as interligações possíveis com todos os outros eixos internos e exteriores das experiências sociais e simbólicas da vida da 
pessoa, da sociedade e da cultura.

Significaria, portanto, um re-centrar da educação. Isto poderia parecer uma enorme perda "de seu lugar próprio", para quem estar acostumado a preservar a educação em um terreno cercado de muros e com raras portas abertas a tudo o mais. Devemos acreditar no oposto. Isto significaria realizar com coragem e criatividade a mesma coisa que desde algum tempo tem sido vivida, entre praticantes e investigadores, no campo da saúde e das artes, para ficarmos aqui com apenas dois exemplos.

\section{Alguns eixos e temas de idéias e de pesquisas}

As identidades pessoais e profissionais dos atores culturais da escola, na escola e ao redor da escola, considerados desde o ponto de vista da integridade de suas existências, dentro e fora do exercício de uma função pedagógica do eixo ensinar-e-aprender. Devolver ao todo da pessoa a dimensão parcial da função profissional (inclusive e principalmente a do estudante).

Os imaginários, as vivências pessoais profundas, os devaneios, as visões de mundo (e não apenas da profissão e do trabalho) dos participantes do mundo da educação.

A interpretação densa da cultura escolar tomada no todo de sua realidade, como sistemas amplos, complexos e profundos de feixes de relações interativas entre teias $e$ tramas de símbolos e de significados. Uma revisita ao desgastado "cotidiano da escola", 
com o olhar ao mesmo tempo arguto e inocente de quem procura descobrir e compreender o acontecimento vivo e inesperado das relações interpessoais, por sob a camada espessa da estrutura dos relacionamentos institucionais.

A abertura desarmada para alguns temas tradicionalmente tabus na prática e na pesquisa da educação: a transgressão da norma; a indisciplina; a formação de grupos e de outras unidades não previstas de interação motivada dentro e fora da escola, principalmente entre alunas e alunos; a sexualidade a as vivências sexuais das pessoas na escola e da escola; a droga, a violência. Enfim, o universo dos processos e produtos para-escolares que assustam ao educador, mas que devem ser considerados como também constitutivos (como acontece no tecido da vida social) de qualquer experiência cultural complexa, como a nossa. Isto significa ousar perguntas novas, desarmadas, e procurar respostas que incidam sobre saberes, sensibilidades e socialidades, mesmo quando perigosamente transgressivas, antes de serem pre-julgados como "problemas".

O foco do olhar sobre a questão dos ciclos, tão psicologizada antes e tão relegada a um segundo plano fora da psicopedagogia.

Deslocar uma análise mais formal e mais exclusivamente orientada pela psicologia para um olhar múltiplo. Sair do ciclo de vida para os círculos culturais da vida em ciclos, pois não se é criança, adolescente, jovem, adulto ou idoso em-si e por razões puramente 
biopsicológicas. Se é e se vive a experiência pessoal e partilhada de cada momento da vida, dentro de mundos de interações com outros (de mesmo ciclo, de outros), de grupos e de círculos de idade e de vocação etária convergente, e também de atribuição social e simbólica de identidades e de significados relacionais a cada categoria "cíclica" de pessoas.

A análise interacionalista e/ou interpretativa de temas também essencialmente culturais como: os processos, mas igualmente as estratégias, os rituais, as alternativas múltiplas nas culturas, as alianças e os conflitos realizados quando da aprendizagem (sempre se aprende uma cultura em uma cultura), da inteligência (o que é ser inteligente para um yanomami?), do ensino, da sala de aula, do currículo.

A pesquisa, a teoria e a crítica aberta para a reformulação ousada não apenas de estruturas e de conteúdos curriculares, mas de todo o complexo de questões e práticas tratadas e vivenciadas na escola. O que deve mudar na educação, quando a educação é repensada através de todas as suas interconexões socioculturais e não apenas através de suas "funções sociais"? A direção ampliada do olhar à experiência pedagógica de outras culturas. Não pensar apenas uma educação indígena desde o ponto de vista de nossas próprias idéias pedagógicas. Algo como uma "educação para os nossos índios". Ir aos índios, aos negros e a tantos outros ouvi-los. Aprender com eles. Saber o que pensam do que nós pensamos, 
como classificam o que classificamos e como praticam o que praticamos, com ou sem o nome de educação. Abrir o leque do que sejam práticas, metodologias e teorias de educação. Rousseau e Piaget foram grandes pensadores da educação. Mas, e Gandhi? E o Dalai Lama?

A questão - que não seja apenas uma novidade - do multiculturalismo na educação. A extensão dele e de suas conseqüências aos direitos humanos. Um esforço para revisitar os direitos humanos e os direitos à educação desde uma perspectiva regida pelo direito à diferença. A responsabilidade da educação em todo este complexo processo não somente como um direito humano, mas como lugar essencial de criação contínua de direitos humanos.

\section{Referências Bibliográficas}

BRUNER, Jerome. Atos de significado. Porto Alegre: Artes Médicas, 1997.

CONSORTE, Josildeth Gomes. Culturalismo e educação nos anos 50: o desafio da diversidade. In: Cadernos do CEDES . Ano XVIII, no 43, dezembro de 1997.

COULON, Alain. Etnometodologia e educação. Petrópolis: Vozes, 1995.

FARIA, Ana Lúcia G. Educação pré-escolar e cultura. São Paulo: Cortez/Editora da UNICAMP, 1999.

GARDNER, Howard. O belo, o bem e o verdadeiro. Porto Alegre: Artes Médicas, 1999. GONÇALVES, Luis Alberto O. e GONÇALVES 
E SILVA, Petronilha. O jogo das diferenças: 0 multiculturalismo e seus contextos. Belo Horizonte: Autêntica, 1998.

LARROSA, Jorge e PÉREZ DE LARA, Nuria (Org.). Imagens do outro. Petrópoois: Vozes, 1998.

McLAREN, Peter. Rituais na escola.

Petrópolis: Vozes, 1992.

MENDES DE GUSMÃO, Neuza Maria.

Antropologia e educação: origens de um diálogo. In: Cadernos do CEDES. Ano XVIII, nํㅡㄴ 43, dezembro de 1997.

TEDESCO, João Carlos. Paradigmas do cotidiano. Santa Fé do Sul: EDUNISC, 1999. TISHMAN, Shari; PERKINS, David e JAY, Eileen. A cultura do pensamento na sala de aula. Porto alegre: Artes Médicas, 1999. TRINDADE, Azoilda L. da. (Org.). Multiculturalismo - mil e uma faces da escola. Rio de Janeiro: DP\&A Editora, 1999. VALENTE, Ana Lúcia E. F. Por uma antropologia de alcance universal. In: Cadernos do CEDES. Ano XVIII, no 43, dezembro de 1997.

1 * Texto apresentado como "Aula Inaugural" do Mestrado em Educação Brasileira. FE/UFG, no dia 23 ** Aposentou-se de marco de 2000.

**Aposentou-se pela UNICAMP e ainda trabalha "voluntariamente" por lá. Está institucionalmente vinculado à Universidade de Uberaba e tornou-se em 2001. Professor Visitante do Programa de PósGraduação em Educação Brasileira da FE/UFG - uma "volta às origens", depois de 25 anos. Algumas de suas muitas obras publicadas testemunham que a educação, ao lado da religião, mundo rural e meio-ambiente, sempre fez parte dos seus temas prediletos de pesquisa. Vale lembrar que $O$ que é educação já passou de 30 edições.

${ }^{2} 1$ Este é justamente o título de um livro que escrevi na década dos 1980, após uma demorada pesquisa de 
campo em uma comunidade rural na Serra do Mar, em São Paulo. Publicado originalmente e com uma versão muito reduzida pela Editora FTD, o trabalho de saber acaba de ser editado pela SULINA, em sua versão completa. Ali eu procuro compreender justamente 0 que é a experiência cultural de estudar, entre crianças e adolescentes cujos cotidianos estão inteiramente imersos na vida e no trabalho rural de uma pequena comunidade camponesa.

${ }^{3} 2$ Berger, Peter e Luckmann, Thomas, A construção social da realidade - tratado de sociologia do conhecimento, 1998, VOZES, Petrópolis, 15ª edição. ${ }^{4} 3$ 1997, Jorge Zahar editor, Rio de Janeiro. Na 11 ä edição, a passagem em questão está nas páginas 49 e 50 .

${ }^{5} 4$ Mas nem sempre. Lembro que ao proferir a sua aula magna no College de France, Roland Barthes escolhe como tema de sua aula: a aula. Ela foi publicada, com este nome, pela Editora Cultrix. ${ }^{6} 5$ Entre os artigos do Cadernos CEDES 43 interfaces do ensino e da pesquisa, ver especialmente os seguintes: antropologia e educação: origens de um diálogo, de Neuza Maria Mendes de Gusmão, culturalismo e educação nos anos 50: o desafio da diversidade, de Josildeth Gomes Consorte, um outro olhar: entre a antropologia e a educação, de Tânia Dauster, e por um antropologia de alcance universal, de Ana Lúcia E. F. Valente.

${ }^{7} 6$ Entre outros, é justo lembrar o nome de Gilberto Velho. Entre aulas no Programa de Pós Graduação em Antropologia Social do Museu Nacional, orientação de alunos de mestrado e de doutorado, participação em congressos e simpósios e também na elaboração de artigos e na organização de livros coletivos, ele tem um, pioneiro, fecundo e responsável pela formação de toda uma geração de "antropólogos da subjetividade". Trata-se de Individualismo e cultura: notas para uma antropologia da sociedade contemporânea. Rio de Janeiro: Zahar Editores, 1981.Em uma direção convergente, mas com uma abordagem bastante original, devo lembrar também de Luís Fernando Dias Duarte, cujos estudos sobre as representações 
46 SILVA, Kátia A. C. P. C. Articulação teoria e prática...

culturais da doença mental e, mais tarde, sobre a idéia e a metáfora da pessoa, constituem hoje um contribuição de inestimável valor. Ver Da Via Nervosa. Rio de Janeiro: Jorge Zahar Editor/CNPq, 1986.

87 Para um conhecimento de síntese das variantes do interacionalismo de síntese, recomendo a leitura de um livro recente de João Carlos Tedesco: paradígmas do cotidiano - introdução à constituição de um campo de análise social, editado pela EDUNISC, de Santa Cruz do Sul, em 1999. A respeito de uma destas abordagens em suas relações com a educação, ver: etnometodologia e educação, de Alain Coulon (VOZES, 1995).

${ }^{9} 80$ primeiro tema é por demais conhecido para citar aqui alguns de seus livros. Lembro que de modo geral a sua bibliografia está dividida em trabalhos sobre metodologias qualitativas na educação e outros, sobre a pesquisado cotidiano na escola. O segundo tema tem produzido trabalhos recentes, a maioria deles traduzidos, como: rituais na escola, de Peter Mc Laren (VOZES, 1992), a cultura do pensamento na sala de aula, de Shari Tisman, David Perkins e Eileen Jay (Artes Médicas, 1999) e atos de significação, de Jerome Bruner (Artes Médicas, 1997) de quem recomendo também os outros livros. Entre os trabalhos quase pioneiros entre nós, lembro alguns entre outros: educação pré-escolar e cultura, de Ana Lúcia Goulart de Faria (Editora da UNICAMP, 1999) , o jogo das diferenças - multiculturalismo e seus contextos, de Luis Alberto Oliveira Gonçalves e Petronilha B. Gonçalves e Silva (Autêntica, 1998). Finalmente, um livro dirigido a professores de sala de aula: multiculturalismo - mil e uma faces da escola, coordenado por Annette Henry Rafael dos Santos (DP\&A editora, 1999).

${ }^{10} 9$ Não tenho números nas mãos e não tenho indicadores a não ser os de minha própria experiência. Quando revejo estes últimos 20 anos de trabalho como professor e como pesquisador, relembro bem poucas ocasiões em tenha encontrado um interesse consistente entre estudantes de ciências sociais, por qualquer assunto relativo à educação. As poucas exceções foram muito boas, porque revelaram 
pessoas de fato motivadas por se especializarem "em educação". Recordo, entre quase 200, uma ou outra "banca de defesa" de dissertações de mestrado ou de teses de doutorado cujo tema tivesse o que ver com a educação. Mesmo entre pesquisadoras e pesquisadores "senior" em nossas universidades, sociólogos e antropólogas devotadas à educação, são, uma vez mais, uma rara exceção. Quase todos os cientistas sociais "da área da educação" trabalham em faculdades de educação. De outra parte, uma mudança curricular nos programas de formação de educadoras e educadores no Brasil, mais aberto a uma integração com o leque das ciências sociais, é ainda pouco ousada.

${ }^{11} 10$ Dei até aqui o exemplo da religião, mas pelo menos do ponto de vista da antropologia, poderia haver dado o da saúde. De fato, feitas as contas, existem muito mais bons estudos a respeito de questões de saúde no Brasil do que a respeito da educação. Tal como a religião, os nossos olhos a saúde se abre como um amplo e denso campo de diferenças e de alternativas a múltiplos olhares. Eles vão desde toda uma ampla gama de pesquisas a respeito das "medicinas populares" e dos diferentes "olhares culturais sobre o corpo", até a análise crítica de políticas oficiais de saúde no País. Dou o meu próprio exemplo. Sempre estive muito interessado em educaçã oe muito pouco em questões de saúde (inclusive a minha). Pois em todos os meus 23 anos de trabalho na UNICAMP, estive às voltas com pelo menos seis orientandas e orientandos de mestrado em antropologia pesquisando questões culturais da saúde. E nenhum no campo da educação, por mais que eu tenha incentivado alguns. 